\title{
CONTRIBUTION TO THE SEAKEEPING ANALYSIS OF MULTIHULL WARSHIPS
}

UDC 629.5.017.2:629.5.022.1:629.5.022.3

Review paper

\begin{abstract}
Summary
This paper analyses in the study of the factors that most affect multihull vessels, and thus determine the feasibility of a new class of ships. It focuses on the impact of service requirements (vessels are typically designed and built under national standards that take into account different factors such as strength, stability, buoyancy, etc.) in a way they are able to withstand extreme environmental conditions with minimal damage, essential for correct and responsible operation. In this paper it is compared, in terms of seakeeping prediction, the results of a monohull with a multihull. In recent years there has been a major breakthrough in this area and it should be noted that although a priori, it may seem that such structures have very good seakeeping characteristics and they provide superior operation compared to traditional monohull with equivalent displacement. They also have some disadvantages such as a higher drag because the wetted surface is higher than its equivalent monohull, and a large weight variation due to their low flotation area. Seakeeping optimization and improving on board comfort aspects are both aspects related to the development of reliable numerical tools as well as knowing a good statistical climatological description. It is crucial to conduct preliminary tests using scale models in a canal with the latest technology for wave generation, test instruments and devices for measuring the movements of the ship and the application of operational criteria. This ensures smaller amplitude movements, high coefficient of floating, sterns mirror, less draft, more beam and metacentric height provide the appropriate natural period.
\end{abstract}

Key words: $\quad$ Seakeeping; multihull vessels; warships; monohull vessels

\section{Introduction}

As the latest literature Nobel Prize in literature Bob Dylan's song "Times are changing”. However, in the latest times, the changes go as fast as the technology changes, and actually, it changes very fast. Naval industry is a very conservative sector where the changes enter very slowly.

However, in order to evolve properly, it must to use technology tools incorporating current improvements of this year that become obsolete just a year later. Naval industry has 
long life cycles and needs to face with many technology changes along the entire lifecycle. The naval industry needs to harmonize these two opposite poles: modern technology and the long building lifecycle of the specific products.

A warship, as shown in figure 1, must face different scenarios, more diverse every day, so it seems necessary to conduct detailed studies in multiple areas that could affect its design. New ship designs with non-standard hull forms are promoting large researches and development programs. As it cannot be otherwise, a warship should be designed according to a future scenario, but this scenario, as Bob Dylan could say, "are changing", and here is where there are uncertainties that a Ministry of Defense (MoD) should anticipate, and prevent, in order to be able to transform the necessity in some appropriate operational requirements.

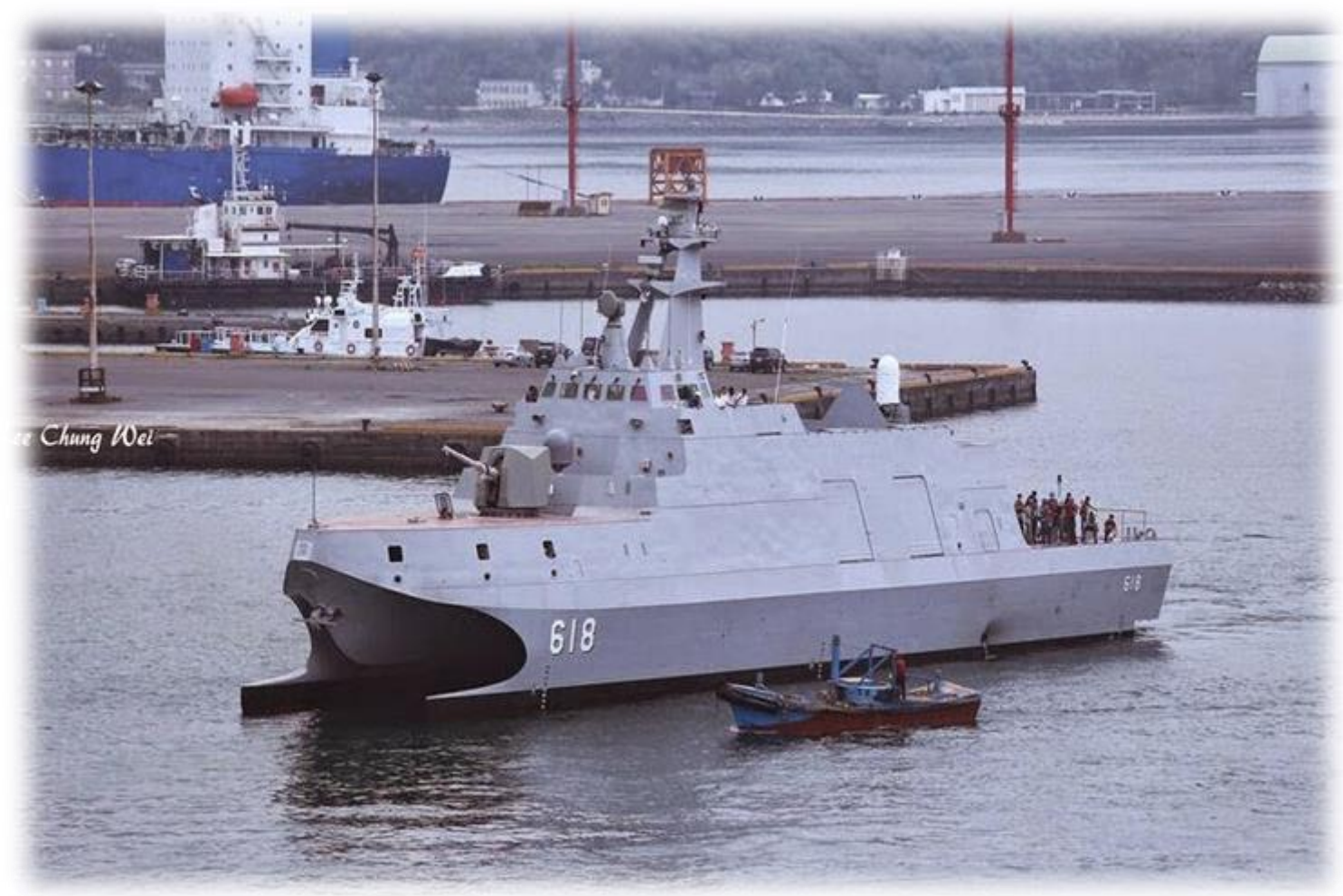

Fig. 1 Chinese multihull warship Tuo Chiang

It must not be forgotten that a single initial factor may completely affect the construction of the vessel, such as a request on the speed or its seakeeping. The concept of seakeeping must be understood from the very early stages of the ship design, looking for an optimal degree for the crew. "Seasickness is to the space, what impatience is at the time" as it was stated by Arthur Schnitzler during the XIX century. For this reason, it is necessary to define where the warship will operate, what kind of sea prevails, and what kind of operations will be carried out.

The platform of the future warship affects in a substantive way its operation and therefore it is necessary to have an expertise (know-how) that will help the MoD in order to evaluate several hydrodynamic alternatives of the project, in the search for a solution end that contributes not only for saving cost and optimization of the ship conditions, but also to increase the safety, fuel consumption, performance of the propeller, its conditions of navigation and movements and accelerations in the sea. The main characteristic to the advance of multihull ships, in terms of resistance, is more complex when it comes to characterize them due to the interaction between the hulls, consequence of the interference 
between the flows surrounding each body, and those produced around a hull as a result of the presence of the other. In addition to the improvement in the seakeeping (behavior associated with the platform in the sea) analysis, there are other developments that allow to get the necessary stabilization during a certain ship operation, predicting and scheming the coming of a quiescent period in advance (Riola and Diaz, 2010) [22] and analyzing the impact on the ship behavior is a minor grade or rank (pitching, rolling and yawing).

Additionally, it must be noted, the comfort level in moderate waves and safety in very big waves are not "the different concepts", because better seakeeping means higher comfort and safety too.

It is known that the rolling induced by the wave movement, produces lateral and vertical accelerations that could affect the crew (Cakici, 2017) [1], cause interruptions in their tasks or deterioration of the load, with serious implications in its stability. In addition, the rolling affects the maintenance of the course following the optimal route prioritizing fuel consumption (Pérez, 2013) [17].

Also the vertical accelerations (heaving) imply a rising of the seasickness rates and affect the effectiveness of the weapons shipped, while complicate the landing and takeoff of aircraft and unmanned aerial vehicles in frigates and aircraft carriers. Some of the most popular devices whose purpose is to reduce the movement of rolling produced by waves (Moaleji, 2007) [14] are anti- rolling tanks, preferably active ones which incorporate a control that alters the natural period of the tank in order to correspond with the natural period (Pérez, 2005) [21].

It must also be taken into consideration the balance keels welded to the hull and located in the bilge of the vessel, the stabilizing fins, as shown in figure 2, which tend to be more effective the greater is the speed of the ship and you exhibit them with mechanisms that allow them to be hidden inside the hull.

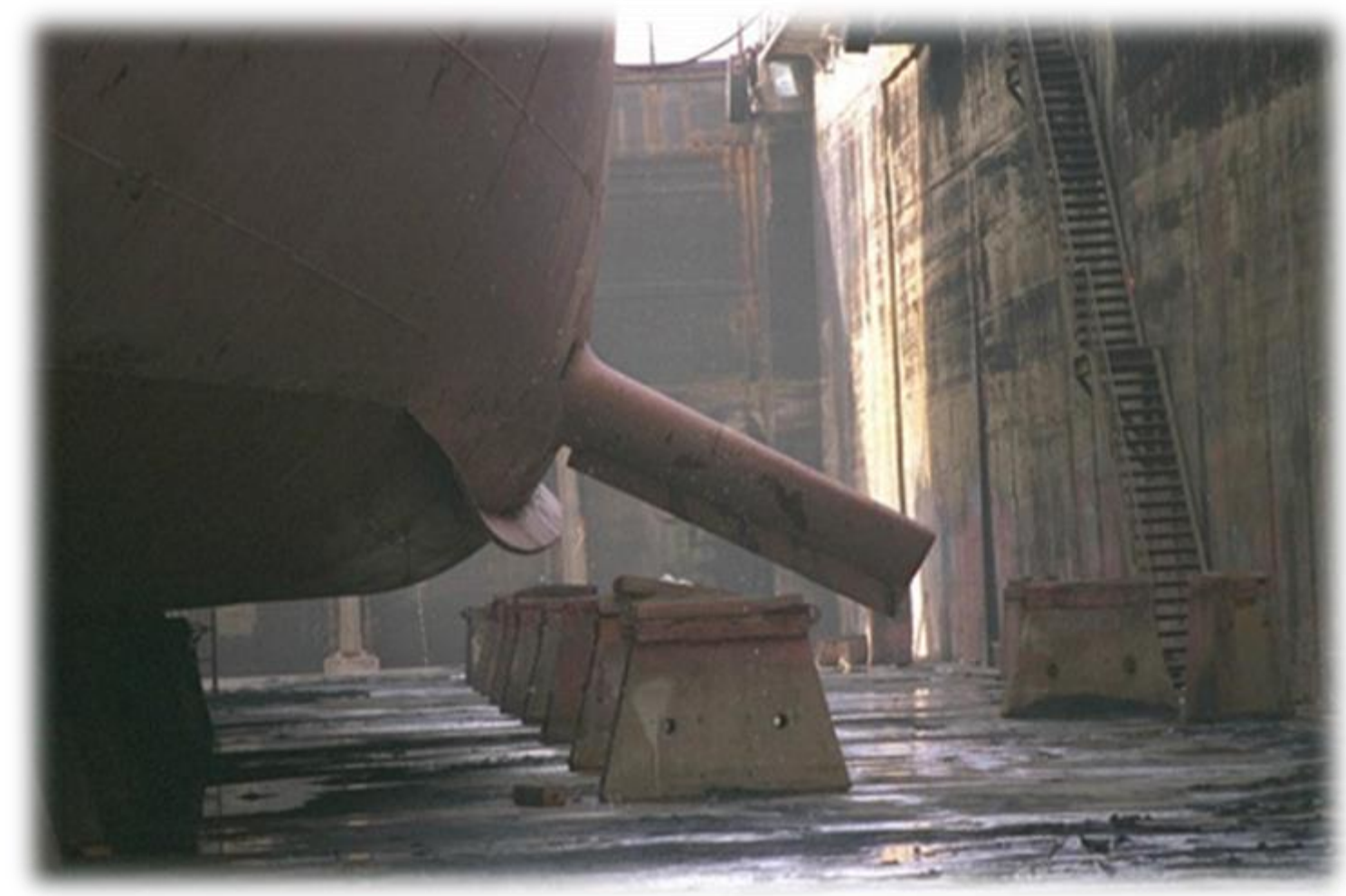

Fig. 2 Anti-rolling devices 
As example of an innovative multihull warships, it could be mentioned the effort of the French Navy in its L-CAT (figure 5) as a program of amphibious forces, an idea of the 90s that it was materialized in 2008 with the construction of a first prototype merging the catamaran concept and landing craft, having in its central part of a lifting platform that allows to modify its configuration when boarding or landing, as well as having been designed to integrate on amphibious vessels of the French Navy.

Derived from this concept, its MoD carried out a contract in 2009 for the construction of four units named Engin de Débarquement Amphibie Rapide (EDAR), figure 3, which offer up to 5 times its shipping capacity.

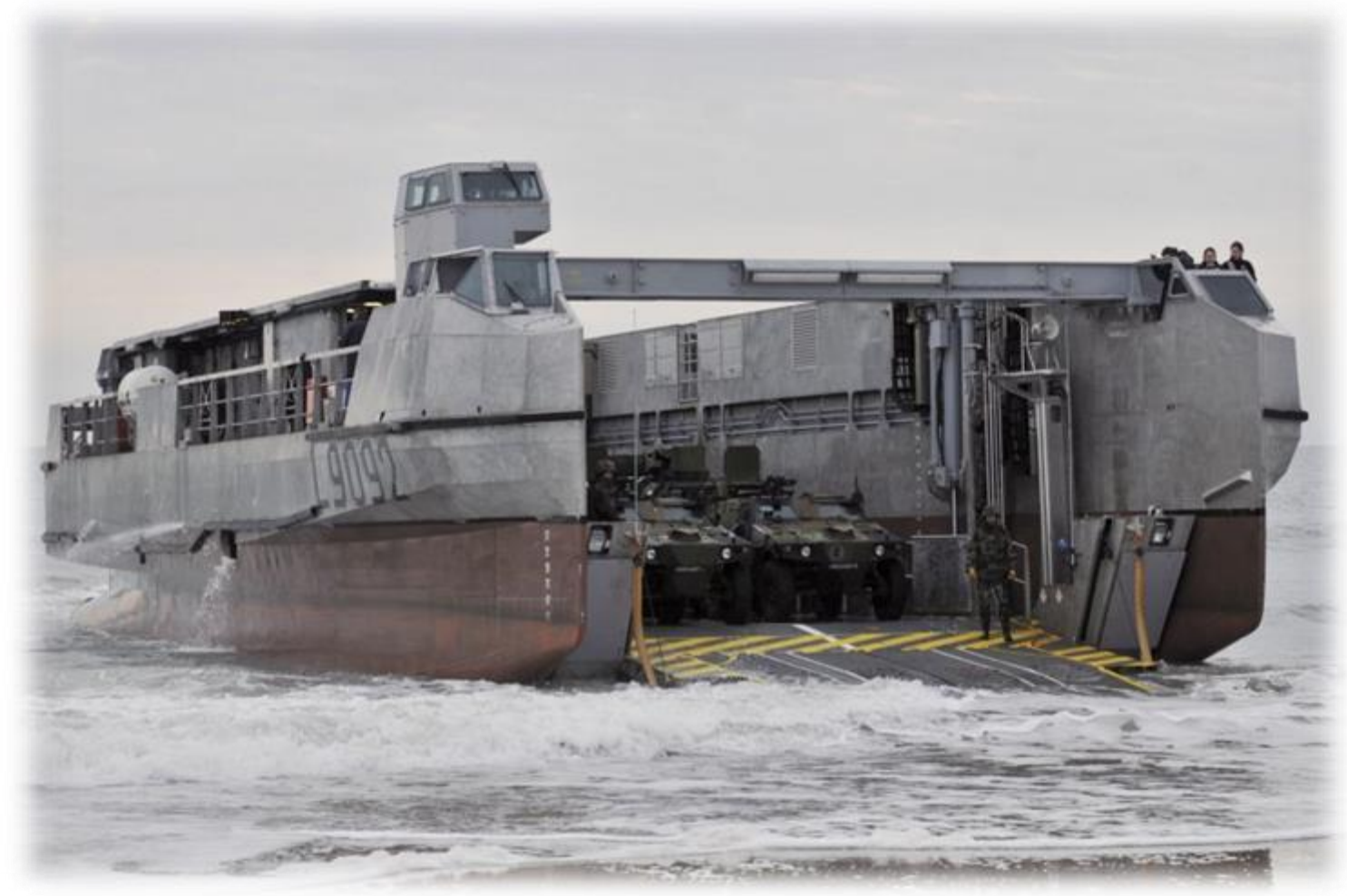

Fig. 3 EDAR during the "Bold Alligator 2012" trials

This acronym represents another concept of multihull vessel whose origin dates back to the $19^{\text {th }}$ century (Ohaeles, 1880) [16], but which would not be until 1968 when the launch of "Duplus", a SWATH, takes place in Holland, a 40 meters length and 1,200 tons ship whose mission was to act as auxiliary vessel to the Offshore Platforms (Kos et al, 2009) [13] and in 1973 when the "kaimalino" was launched in San Diego and the SWATH acronym was created by the US Navy.

At the end of the XX century the design and construction of this type of vessels was generalized and its greatest design highlight was the Shadow IX-529, built by "Lockheed Missiles and Space Company" which had two twin hulls, each with a propeller.

The shown examples of multi-hulls seem more or less accidental; it seems, the author has not a general view on contemporary application of multi-hull ships. For example, the book of Victor Dubrovsky [4]. 


\section{Designing the hull forms}

When these type of ships (multihulls), are being designed, Naval Architects \& Engineers focus on improving the main characteristics of these hull forms, increasing L/B-ratios, designing ships thinner and slender rather than the traditional equivalent monohull, in order to take advantage as regards the total resistance of the ship (i.e. Frictional resistance is increased in multi-hulls, while wave resistance is reduced).

These different ways of hull forms definition minimize the wave resistance, which highly depends on the speed (Holtrop and Mennen) [9], see equation 1, allowing multihull vessels to reach higher speeds.

$$
R_{\text {Waves }}=k \cdot \nabla \cdot \rho \cdot g \cdot \mathrm{e}^{\left(m_{1} \cdot F_{N}{ }^{d}+m_{2} \cdot \cos \left(\lambda \cdot F_{N}^{-2}\right)\right.}
$$

Another feature of the side hulls refers to their symmetry / asymmetry, understood as that which is observed from the division of the volume of the hull by the theoretical plane from the ship center line.

There is not a fixed rule on which hull forms are the most appropriate, this is why it is necessary to do an analysis of different alternatives in each project depending on the speed and separation or distance between hulls.

From a hydrodynamic point of view, there are software Computer Aided Design (CAD) tools, see figure 4, capable of incorporating different aspects of almost automatically.
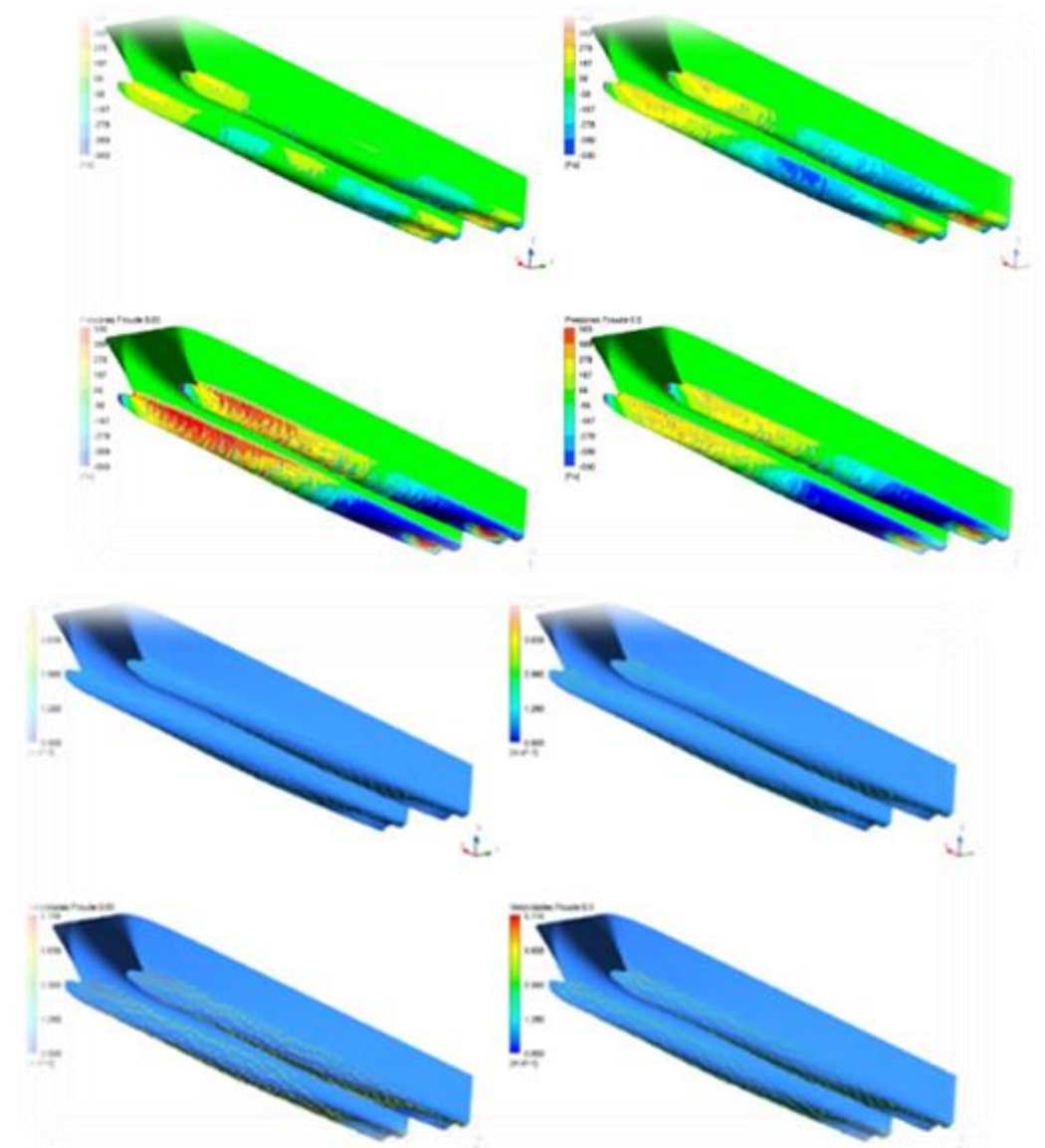

Fig. 4 Pressure and speed distribution on the hull of a catamaran vessel 
As few examples to mention: the FORAN System (Pérez et al., 2015) [18], probably the older shipbuilding CAD tool in the market; the FRIENDSHIP tool (Nowacki et al., 1995) [15] which incorporates a technique of modeling based on generation of parametric curves, whose first approximation was made at the end of the past century (Harries and Abt, 1998) [8]; and the (FRONTIER) [6] or (SHIPFLOW) [27].

When designing, there are today more references as (Grigoropoulos, 2004) [7] which proposed a dual scheme to optimize forms according not only to the resistance factor (see figure 5) but also to the seakeeping.

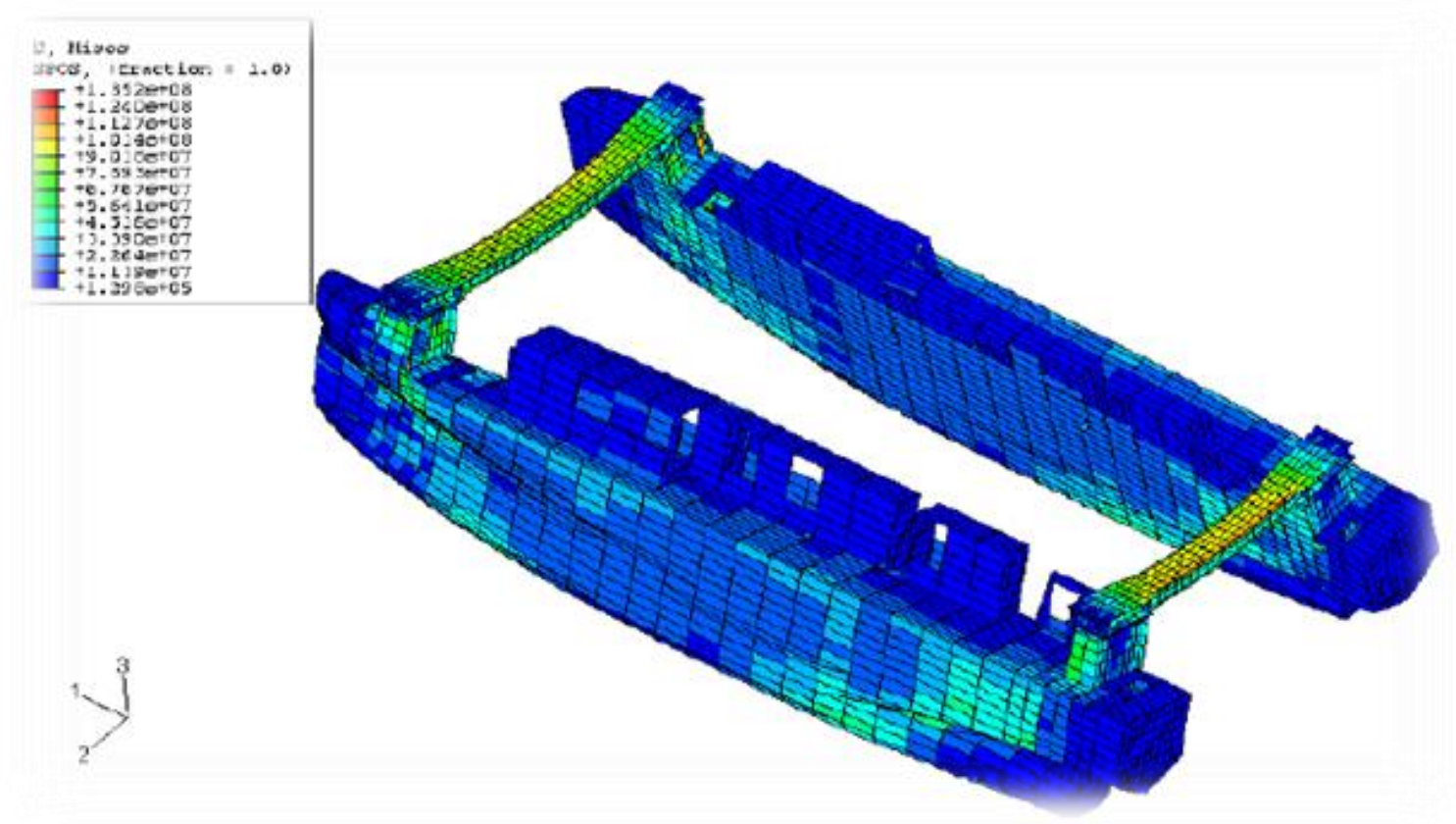

Fig. 5 Structural integrity of the L-CAT project

More contemporary application of multihull ships focused on resistance and seakeeping behavior can be obtained in (Dubrovsky and Lyakhovitsky, 2001) [3], (Dubrovsky, 2010) [4] and [5], (Katayama, et al, 2011) [11] or (Kim and Yang, 2011) [12].

\section{Results and discussion}

The seakeeping is a measure of the ability that has a floating structure to be adapted to the sea conditions.

In the famous engraving "The great wave of Kanagawa" by the Japanese artist Katsushika Hokusai, it appears a small fishing boat capable of surviving great waves, but it is far from being a comfortable condition for the fisherman who is on board.

These two different concepts, survival and comfort, are the critical ideas to keep in mind during the design of any floating structure when subjected to a certain type of sea (Perez and Lamas, 2011) [19].

To successfully perform a study of seakeeping, it is mandatory to model the behavior of sea in which it has to navigate the vessel, so the most common sea conditions, as the toughest which will be found to originate the spectrum of waves that will analyze their behavior. Below, in figure 6 , it is shown the data that could be obtained through the official website of Puertos del Estado (www.puertos.es), which would present the annual significant height, the 
annual peak period histogram, as well as the rest of necessary values to identify the sea condition.

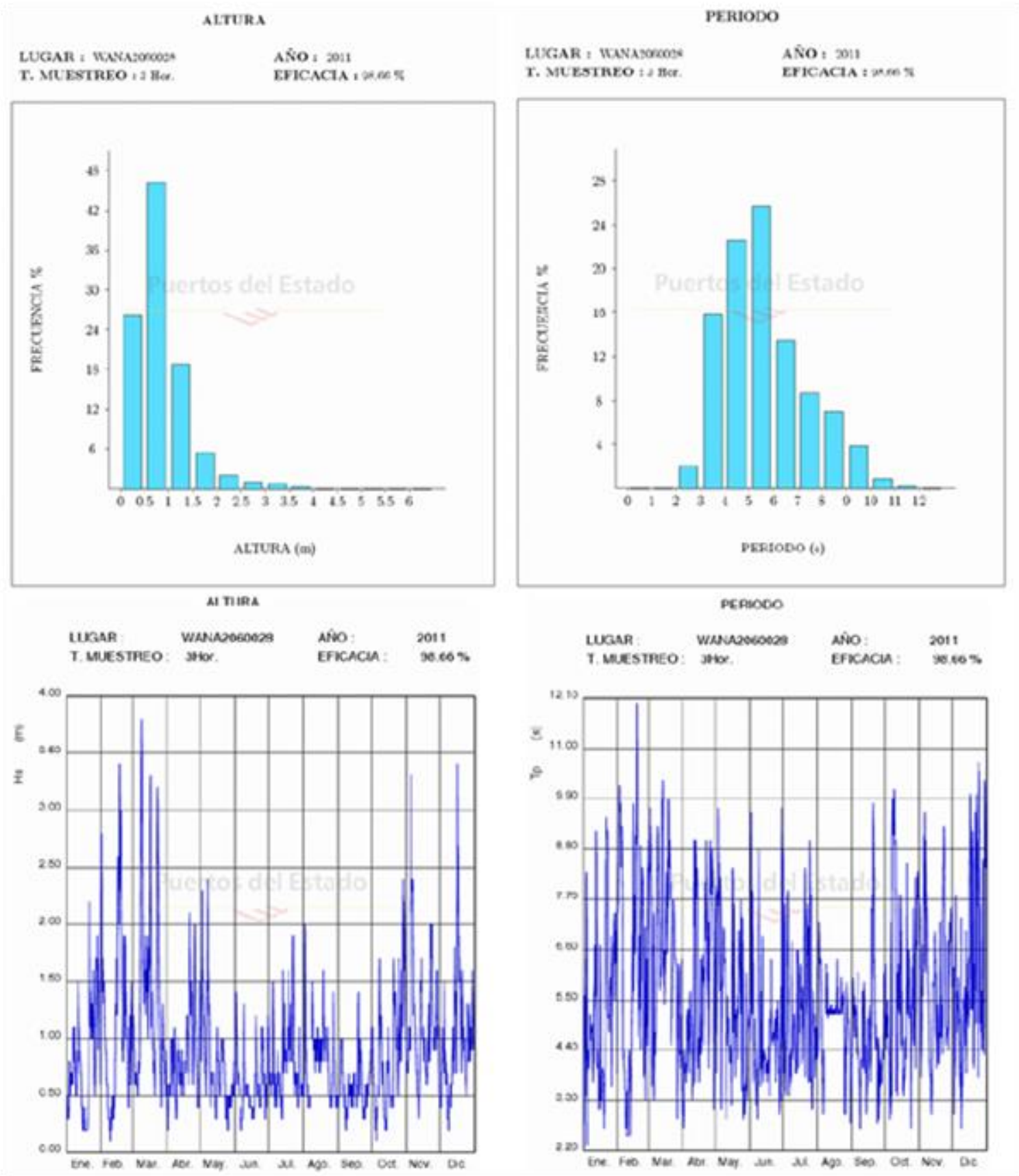

Fig. 6 Representative of the sea condition charts

Seakeeping directly impacts on the design of the ship. Both, main dimensions and general arrangement of the spaces are taken into account in order to consider the movements of the vessel. Thus, it fits within the design of the vessel or design stage as it is shown on figure 7. This process describes the method as a sequence of specific design disciplines, both of synthesis (geometry of the hulls, layout, etc.) and analytical (stability, seakeeping, etc.) in order to achieve an optimal design that meets the requirements, although its complexity is due to some of these disciplines incorporate hundreds of activities within it and the seakeeping is a good example (Pérez and Lamas, 2011) [19]. 


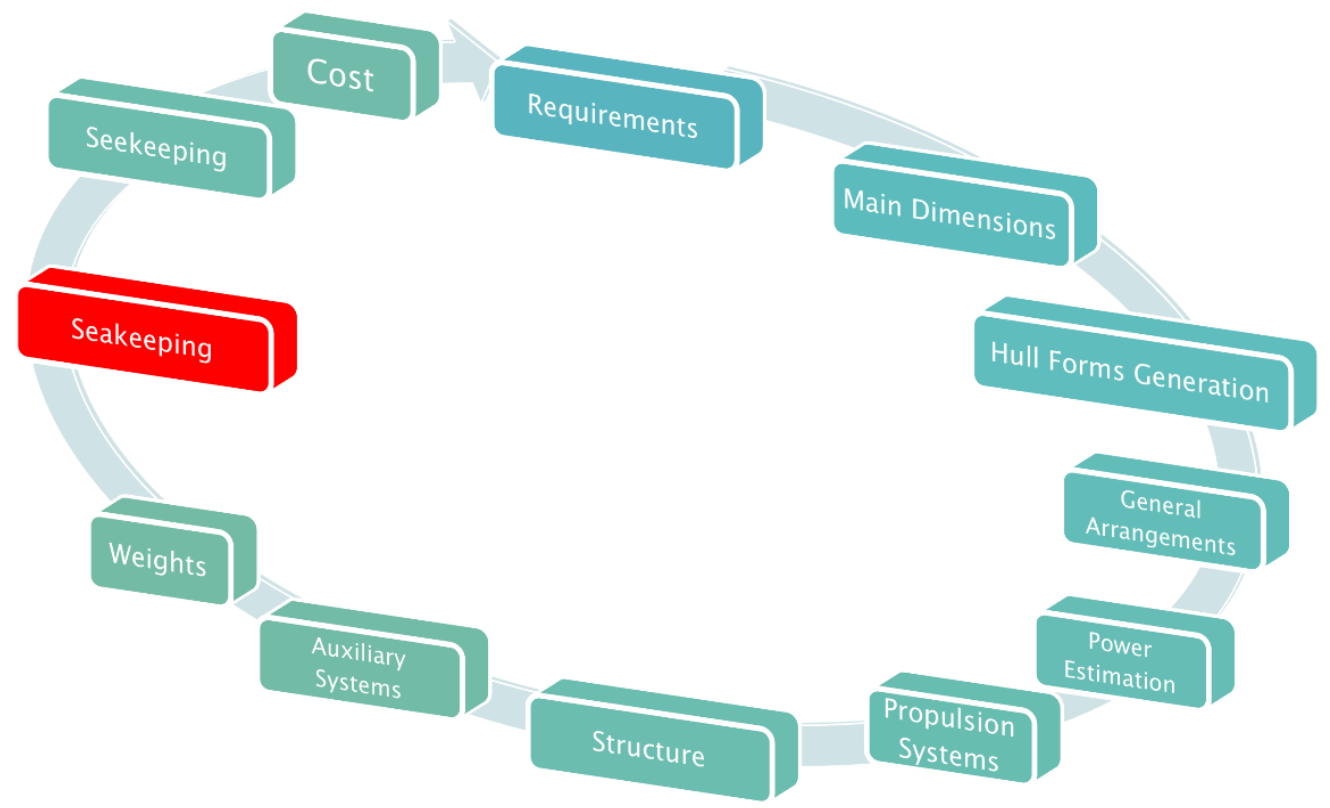

Fig. 7 Traditional ship design process

In fact, the seakeeping characteristics of the vessel, as the one in figure 8, depend on so many interrelated factors that it is virtually impossible to state what will happen if a specific hull forms change is made without a reasonable analysis. This is because the seakeeping depends not only of the response in movements, but also the marine environment in which it is located. The ship in the sea, submitted to the acting forces, moves according to six degrees of freedom.

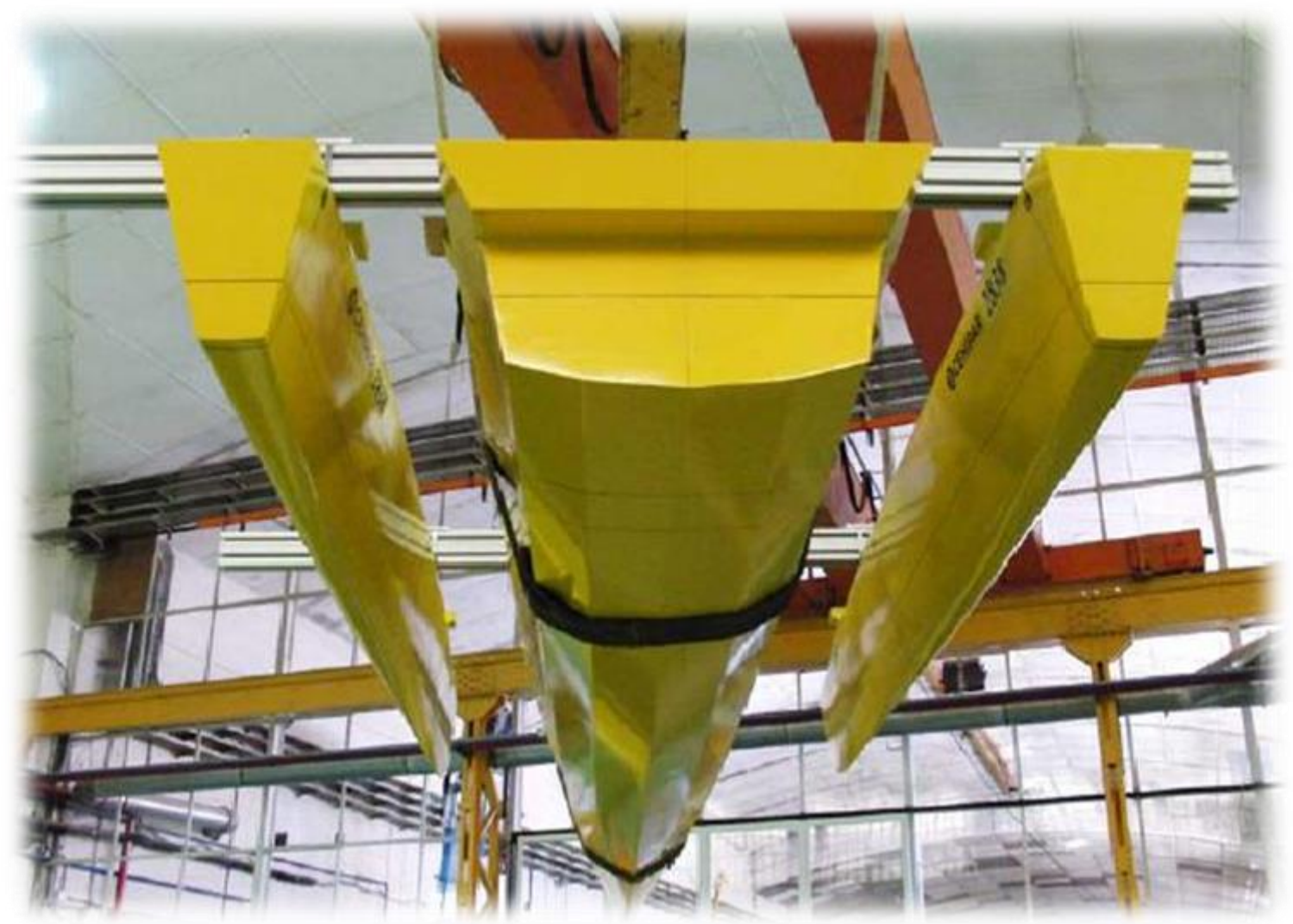

Fig. 8 Trimaran tested at the CEHIPAR 
All kinds of ship movement may be divided into three types of linear motion and three types of rotational motion.

As regards linear ones: motion along the longitudinal axis (surging), motion along the transverse axis (swaying) and motion along the vertical axis (heaving).

Concerning rotational motion: motion around the vertical axis (yawing), motion around the transverse axis (pitching) and motion around the longitudinal axis (rolling).

It can in general be stated that the outwardly directed centrifugal accelerations brought about by any rotational motion are not significant. This accordingly applies to yawing, pitching and rolling.

Some of the typical calculations obtained and discussed with the aim of knowing how it would perform the ship in sea conditions previously described are shown in the figure 9 . The idea is to calculate the values of $\mathrm{m}_{0 \theta}, \mathrm{m}_{0 \phi}, \mathrm{m}_{0 \mathrm{z}}$, i.e. the moments of order zero of such curves $\mathrm{S}(\mathrm{w})$ or spectral density of response for each movement, representing the area beneath these curves and identify the greatest value for different directions and design speed.

These values give an idea of the energy which has the ship in the three main movements affecting the vessel determining the critical paths for each movement. This is made using polar diagrams, proposed by Comstock et al. [2], which represent a specific value depending on the course and speed. Below, figure 9, are these diagrams for each movement and sea condition. It is important to reflect that these polar diagrams are not used only for naval but also for commercial ships and small craft using different seakeeping criteria.
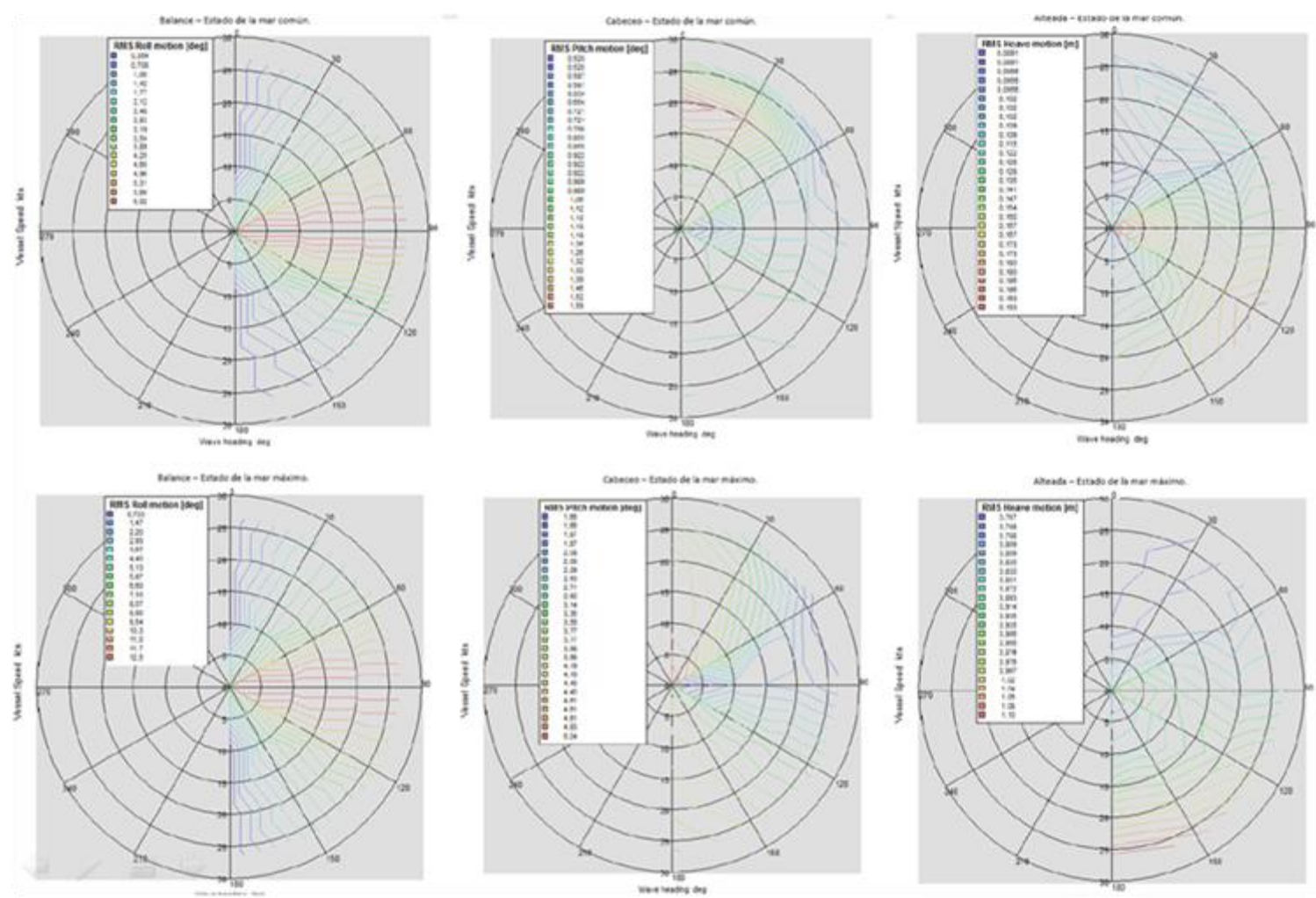

Fig. 9 Movements by the action of the waves

Thus, the movements are defined by the six degrees of freedom that this ship can experience. From the polar diagrams for this ship, it could be obtained the following 
conclusions: in the case of rolling in normal conditions, maximum is obtained with seas with crosswise direction, reaching rolling values of $12.75^{\circ}$, which are not worrisome.

When it is concluded that there is a maximum sea condition, it will be also considered non parallel sea direction, reaching rolling of $26.41^{\circ}$, so would be recommend to change the course for improving the rolling.

As regards pitching, under normal sea conditions, the maximum value would be on following seas about 20 knots, reaching values of $3.32^{\circ}$, so would be recommend to modify the speed to reduce added resistance due to waves, while for rough seas, the maximum would be also obtained with following seas at very low speeds, although for head on seas at high speed also presents a maximum, reaching pitching values of $9.32^{\circ}$, so would be recommended to slow down and change the course.

The same conclusions can be obtained for the movements of yawing, where in normal conditions the maximum occurs in directions of $120^{\circ}$, with value of $0.386 \mathrm{~m}$, being low enough as to not be taken into account and with rough sea the maximum would be for head on seas, with a value of $2.245 \mathrm{~m}$.

Seven is the number of factors that mainly affect the responses of the ship. Its size, its dimensions, the hull forms, the weight distribution, displacement, stability and freeboard. There are also several ways of estimating the seakeeping of a vessel and the results of some of these calculations or model tests are transfer functions called Response Amplitude Operators (RAOs).

The use of numerical simulations to predict the response of a ship is very useful, since it provides a cheap way for determining a lot of alternatives from an early stage of the design. Once the design has converged to one or two alternatives, these can then be tested in a towing tank with a greater degree of reliability. To calculate the ship response navigating in waves is a non-linear phenomenon, involving the dynamics of the ship and the hydrodynamic forces.

Although different nonlinear analysis have been presented by different authors, for many applications the order of the nonlinear is sufficiently small so a linear theory would provide adequately accurate results. Thus, numerical calculation methods for predicting the RAOs, can be divided into two large groups: in the time domain and in the domain of the frequency (Pérez, 2012) [20].

The frequency domain methods are simpler and less intensive in the calculations. Most of the Strip Theory use these methods dealing with the ship movements as low-amplitude sinusoidal movements. The two major limitations that present are that vessels must be sufficiently slender and the Froude number not too high. The hydrodynamic characteristics of its sections are calculated, assuming 2D in viscous flow, without interference by upper sections. From these values, the coefficients of the motion equations and its response to the waves are calculated. Thus, the Strip Theory is an excellent tool for the preliminary design or where the scale of the project does not allow a detailed analysis of the seakeeping.

Methods which use the time domain, could define the wave which passes around the hull forms. In small incremental time steps, instant net force integrates the water pressure and the friction forces in each part of the hull. The acceleration in the hull integrates time to calculate the new speed and position of the vessel.

The numerical tools for the prediction of seakeeping have not yet reached a stage of sufficient maturity and numerical techniques must be related to the test results in towing tanks (Pérez and Lamas, 2011) [19].

The Strip Theory could provide important information regarding the seakeeping on trimarans and be used in numerous situations. Thus, to calculate the movements in remote locations, trimaran assume rotation about the center of gravity and therefore the distance to 
the remote location from that center of gravity is quite important. In the study has been calculated this distance internally, and all the positions have been measured in a coordinate system.

Strip theory is a robust tool for seakeeping calculations. 3-D Rankine source method works also quite well, especially at higher speeds (Sclavounos, 1996) [26].

The main advantage of the trimaran studied for this paper is to have an smaller floating area rather than its equivalent monohull, as well as a smaller longitudinal inertia moment and a longitudinal metacentric height (Riola and Perez 2012) [23] (Tang, 2019) [28].

The reduced buoyancy is a necessary but not sufficient condition to ensure a good seakeeping. And because the two lateral hulls it is possible to reduce vertical oscillation, and increase the righting arm at high speeds.

In each relative position of the trimaran as solid-rigid, receives the pressures and impacts, plus other local effects, the acceleration forces and the speed affecting each point as the same moving parts rigid.

In this technical paper, the spectrum used has been the Bretschneider one or the International Towing Tank Conference (ITTC). It is useful to define the idealized wave spectra, equation 2, which widely represent the characteristics of the real energy spectra of the wave.

$$
S_{\text {ITTC }}(\omega)=\frac{A}{\omega^{5}} \cdot \exp \left(\frac{-B}{\omega^{4}}\right)
$$

Where the coefficients A and B are defined as it follows:

$$
\begin{aligned}
& A=172.75 \cdot \frac{\bar{H}_{\text {char }}^{2}}{\bar{T}^{4}} \\
& B=\frac{691}{\bar{T}^{4}}
\end{aligned}
$$

Both parameters depend on the significant wave height, $\bar{H}_{c h a r}$, and the average period $\bar{T}$. Information about the characteristics of the wave, studied in the Mediterranean Sea, is given in the reference (Riola and Perez, 2012) [23]. The different calculations of spectral moments are given by the following equations, where the significant wave height is described as:

$$
\bar{H}_{\text {char }}=4 \cdot \sqrt{m_{0}}
$$

Where $m_{0}$ it is defined as:

$$
m_{0}=\frac{A}{4 \cdot B}
$$

The average period could be expressed as it follows: 


$$
T_{Z}=0.92 \cdot \bar{T}
$$

The zero-crossing period parameter is defined as the mean time interval between upward or downward zero crossings on a wave record.

The influence of wave height and period statistics on design will be illustrated with wave run-up at sea dikes, or more general, sloped structures. For a certain range of wave steepness and slope angle $\alpha$ the wave run-up $R$ of regular waves can be characterized by the formula which is based on (Hunt, 1959) [10]:

$$
R=1.27 \cdot H^{0.5} \cdot T \cdot \tan \alpha
$$

For irregular waves usually the parameter $R_{u 2 \%}$ can be written in the following form:

$$
R_{u 2 \%}=a \cdot \bar{H}_{\text {char }}{ }^{0.5} \cdot \bar{T}_{\text {char }} \cdot \tan \alpha
$$

$\bar{H}_{\text {char }}$ and $\bar{T}_{\text {char }}$ are characteristic wave parameters from time-series or spectral analysis. $\bar{H}_{\text {char }}$ is generally accepted to be the significant height $H_{1 / 3}$.

Thus, the Bretschneider contains all frequencies of the wave. This is the reason why the average period between peaks is zero, because there will be infinitesimally small ripple with adjacent peaks (equations 10 and 11):

$$
\begin{aligned}
& H_{1 / 3} \approx 4 \cdot \sqrt{m_{0}} \\
& \bar{H}_{\text {char }} \approx H_{1 / 3}
\end{aligned}
$$

The modal period can be found between the wave spectrum energy and finding the maximum (peak $=0$ ) (equation 12):

$$
\begin{aligned}
& \omega_{0}=\sqrt[4]{\frac{4 \cdot B}{5}}=\frac{4.849}{\bar{T}} \\
& T_{0}=1.296 \cdot \bar{T}=1.41 \cdot \bar{T}_{Z}
\end{aligned}
$$

The added calculated resistance is due only to the movement of the trimaran in waves. For this study, the method applied is the Salvesen method [25] which is based on calculating the longitudinal strength of second-order wave affecting trimarans.

This method is valid in the most problematics navigations and can be applied with a reasonable accuracy up to approximately $20^{\circ}$. The square root media spectrum, $\mathrm{m}_{0}$, it is the area under the spectrum and gives a measure of the total response of the trimaran. It is 
possible to get different results from the analysis of the trimaran based on each frequency. RMS is the Root Mean Square, and for this study the significant amplitude is twice the value of the RMS.

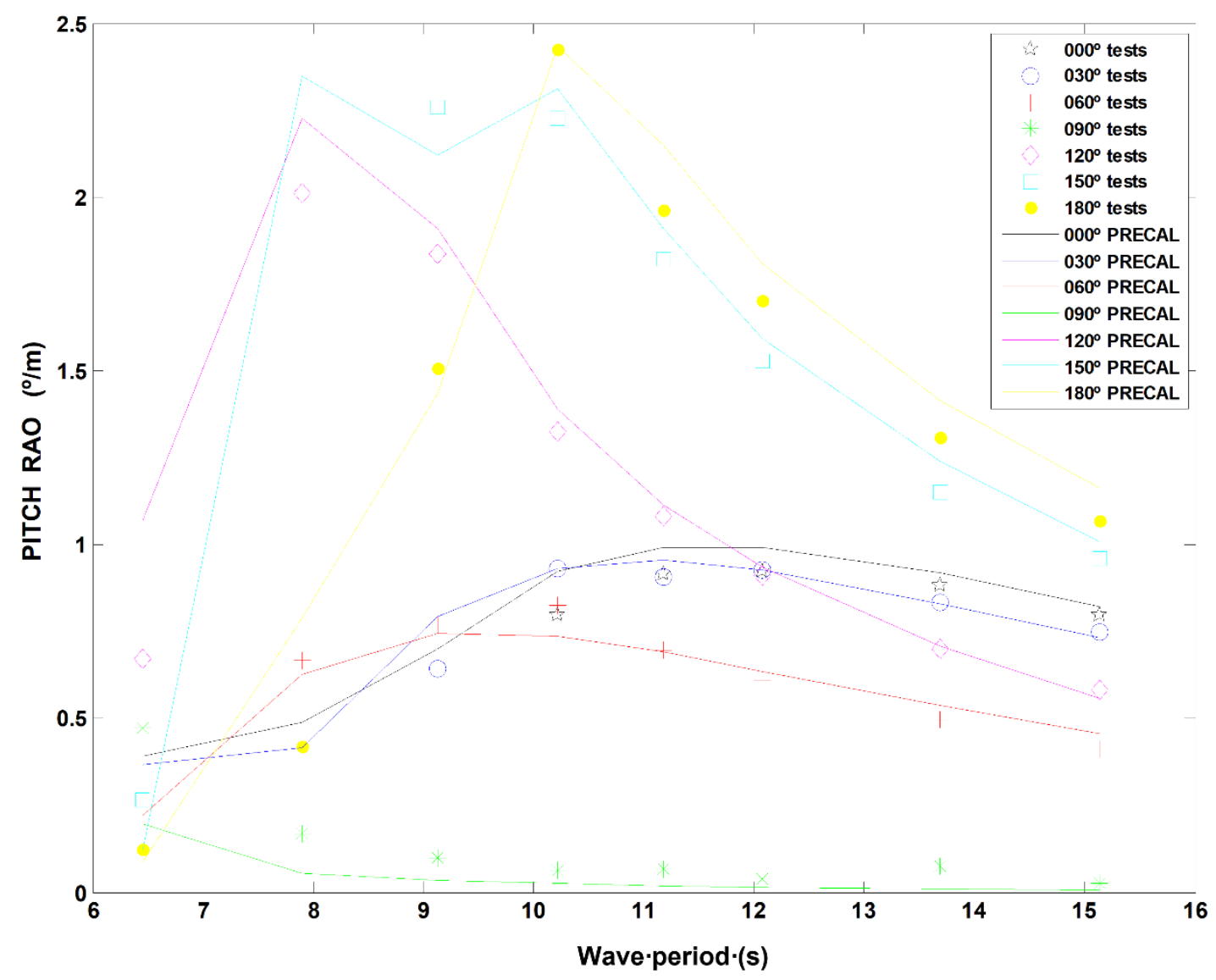

Fig. 10 Amplitude of the RAO of pitching for 25 knots

Spectral conditions of sea representations are key to determine the response of trimarans in the sea. The RAOs (figure 10) tend to one in low frequency, where the trimaran moves simply up and down with the tide and behaves like a cork. In high-frequency the response tends to zero, because the effect of many short waves, is contrasted with the length of the trimaran. It will have a typical peak higher than one because is close to the natural period of the trimarans, due to the resonance.

A greater RAO value than one, indicates that the response of the trimarans is greater than the amplitude of the wave (Riola et al., 2013) [24]. Due to its complexity, analysis of seakeeping usually ends in a late stage of the ship design process using computer applications.

Although these calculations can be performed successfully in monohull vessels, at the moment these calculations are not optimal in the design of innovative hull forms of multihull vessels. The recent interest in catamarans and trimarans, raises unknowns to the naval sector, while there are not accurate application tools for calculating their seakeeping. 


\section{Naval seakeeping applications}

From naval architect experiences with naval warships, we are aware of a large number of seakeeping issues in the ship design for operational purposes, as for example, relate to crew performance, as affected by seasickness, reduced mobility or fatigue. These are governed by the vertical and transverse accelerations and to some extent by slamming induced vibrations. The issues related to vertical motions, figure 11, and accelerations and relative wave elevation in the fore ship are typically most critical in head and bow quartering seas. Rolling related issues are critical at the heading where resonant roll conditions occur. Course keeping and broaching are critical at moderate speed in steep waves yielding low encounter frequencies, i.e. in stern waves.

Other examples as damage on the fore deck, determined by the shipping of green water and its dispersion on the fore deck, spray development in the bow flare, helicopter operations as vertical replenishment, limited by the vertical velocities and accelerations and the transverse accelerations at the helideck, rolling and the performance of fin stabilizers or course keeping and related risk of broaching in waves from the stern quarter, must be controlled, validated and supervised. And all this great amount of results, data and developments are those that will give us the operational optimization of the ship.

\section{VERTREP en SS5 $(\mathrm{Hs}=3.25 \mathrm{~m}-\mathrm{Tp}=9.7 \mathrm{~s})$}

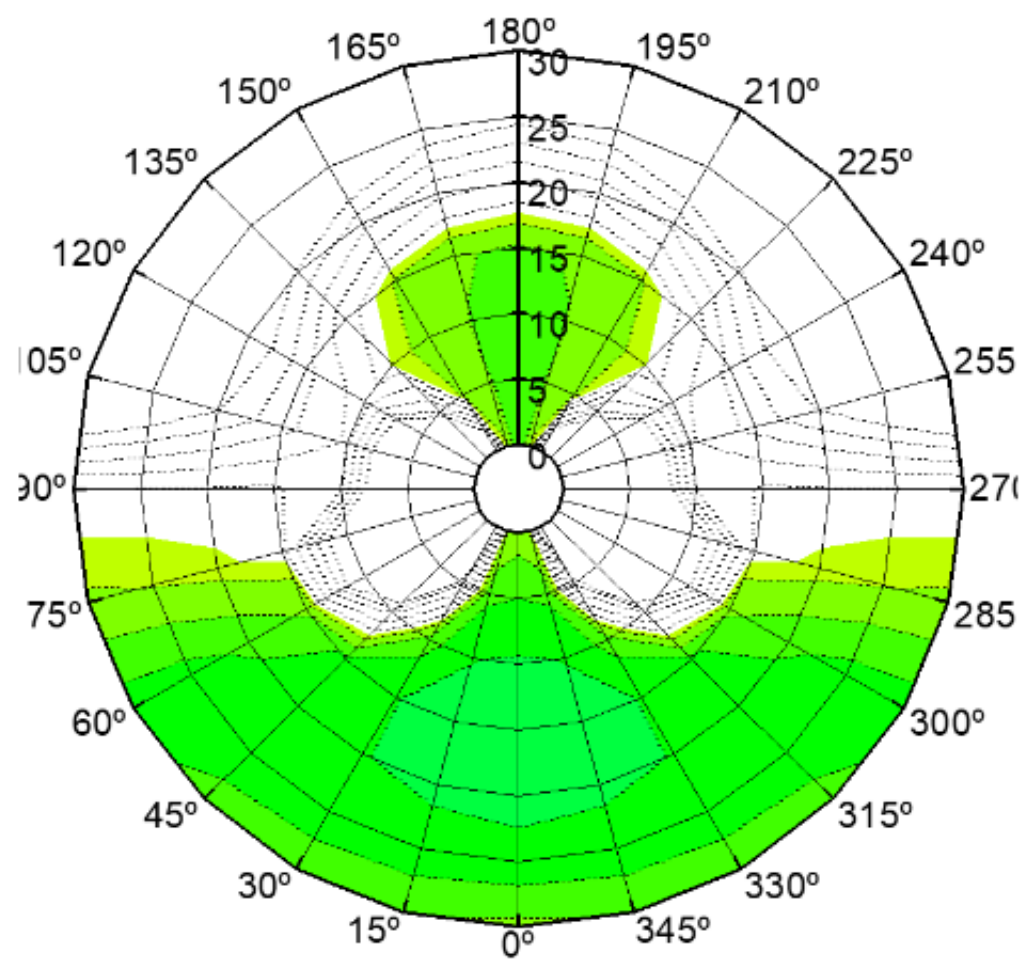

Radial component: ship speed (knots)

Circumferential component: waves course (degrees)

Fig. 11 Limits of vertical replenishment (VERTREP) 


\section{Conclusions}

This highlight that there are too much work remaining ahead in the prediction of the seakeeping, as to compare the results of a monohull with a multihull vessel, although there has been in recent years an important advance in this area as this paper carried out for a trimaran in which we have obtained results that allow a rigorous comparison with traditional monohull platforms.

It has been proven that Computer Fluid Dynamic (CFD) applications normally used for conventional ships, can be used in this type of multihull vessel, with, in general, satisfactory approximations to the experimental results, which is a great time and money saver facing optimizations of hull forms for these types of vessels. It should also be taken into account to analyze the pressure distribution calculated under the hull when the optimization of hull forms. Seakeeping results show that the trimaran hull forms is satisfactory, with similar performance rather than a monohull with same displacement. A detailed study of the appendices should certainly introduce substantial improvements.

The response of a vessel to a certain sea condition depends on its weight, the righting arm and the characteristics of the waves. When the righting arm is smaller, in the cases of pitching and rolling, greater is the period of motion.

When studying the seakeeping of a vessel, there are four natural factors to keep in mind: topography, tides, currents and winds. Of these factors, there are two with a far superior importance: wind and waves.

Seakeeping optimization and other aspects of improvement of the comfort on board, need reliable development of numerical tools, as well as knowing an appropriate weather statistical description of the operation zone.

It is compulsory to manage test scale models in a towing tank with generation of waves and an operating criteria, aimed to ensure movements of lower amplitude, high flotation coefficient, less draft, more beam and metacentric height which provide the suitable natural period. Nowadays computers have facilitated this problem but, for the moment, they cannot replace tests in toeing tanks.

Finally point out that the incorporation of multihull vessels in the shipbuilding industry has pass borders, and this type of ships is becoming a current trend of construction for different navies as opposed to monohull structures, always starting from the premise of the needs and typologies in which these units are applicable.

\section{Acknowledgments}

We offer our regards and blessings to all of those who supported us in any respect during the completion of the technical paper.

\section{REFERENCES}

[1] Cakici, F. et al. Prediction of the vertical motions of the DTMB 5415 ship using different numerical approaches. BRODOGRADNJA. Vol. 68. N. 2. pp. 29-44. 2017. https://doi.org/10.21278/brod68203

[2] Comstock, E.N. and Keane, R.G. Seakeeping by Design. Naval Eng. Journal, April 1980. https://doi.org/10.1111/j.1559-3584.1980.tb05267.x

[3] Dubrovsky, V.A. and Lyakhovitsky, A. Multi-hull ships. Backbone Publishing Co., Fair Lawn, USA, 495 p. 2001.

[4] Dubrovsky, V.A. New options and scientific developments. Ships and Offshore Structures. Taylor \& Francis, USA. 2010. https://doi.org/10.1080/17445300903149038

[5] Dubrovsky, V.A. Multi-Hulls: Some New Options as the Result of Science Development. BRODOGRADNJA. Vol. 61. N. 2. pp. 142-152. 2010. 
[6] FRONTIER. Multi-Objective design environment (mode) FRONTIER. User Manual. 2002. ES.TE.CO s.r.1.

[7] Grigoropoulos, G. Hull form optimization for hydrodynamic performance. Marine Technology. 2004. Vol. 41 (4). pp. 167-182.

[8] Harries, S. and Abt, C. Parametric curve design applying fairness criteria. International Workshop on Creating Fair and Shape-Preserving Curves and Surfaces. 1998. Berlin/Potsdam, Germany: Network Fairshape.

[9] Holtrop, J. and Mennen, G.G.J., A statistical power prediction method, International Shipbuilding Progress, Vol. 25, October 1978. https://doi.org/10.3233/ISP-1978-2529001

[10] Hunt, I.A. Design of Seawalls and Breakwaters. Proc. ASCE, Journal of the Waterways and Harbors Division. 1959. Vol. 85, No.WW3.

[11] Katayama T., Kotaki M. and Ikeda Y. A Study on the Characteristics of Roll Damping of Multi-Hull Vessels. In: Almeida Santos Neves M., Belenky V., de Kat J., Spyrou K., Umeda N. (eds) Contemporary Ideas on Ship Stability and Capsizing in Waves. Fluid Mechanics and Its Applications, vol 97. Springer, Dordrecht. 2011. https://doi.org/10.1007/978-94-007-1482-3_27

[12] Kim, H. and Yang, C. Hydrodynamic Optimization of Multihull Ships. 11th International Conference on Fast Sea Transportation FAST 2011, Honolulu, Hawaii, USA. 2011.

[13] Kos, S. et al. Comparative analysis of conventional and SWATH passenger catamaran. Proceedings of International Conference on Transport Science. 2009. Portorož, Slovenia: Slovenian Society for Transport Science and University of Ljubljana Faculty of Maritime Studies and Transport.

[14] Moaleji, R. and Greig, R. On the development of ship-anti-roll tanks. Ocean Engineering. 2007. Vol. 34. pp. 103-121. https://doi.org/10.1016/j.oceaneng.2005.12.013

[15] Nowacki et al. Computational geometry for ships. London, UK: World Scientific Publishing Co. Pte. Ltd. 1995. https://doi.org/10.1142/2633

[16] Ohaeles, G. Patent EEUU No. 234794. 1880.

[17] Pérez, R. The seasickness as marine problem. Case Study. Journal of Marine Science and Application. 2013. January. pp. 58-64. https://doi.org/10.1007/s11804-013-1172-y

[18] Pérez, R. et al. A next-generation of 3D CAD tool for basic ship design. Ingeniería Naval. September. N. 939. 2015.

[19] Perez, R. and Lamas, M. El comportamiento en la mar en estructuras flotantes. Revista ANALES. 2011. January-February. pp. 24-29.

[20] Pérez, R. Seakeeping in the navigation. International Journal for Traffic and Transport Engineering. 2012. Vol. 2 (3). pp. 221-235. https://doi.org/10.7708/ijtte.2012.2(3).05

[21] Pérez, T. Ship motion control. London, UK: Springer-Verlag. 2005.

[22] Riola, J. and Díaz, J. Predicción de periodos quiescentes en buques (QPP). 49 Congreso de Ingeniería Naval e Industria Marítima. 2010. Bilbao, Spain.

[23] Riola, J. and Pérez, R. Seasickness phenomenon. Journal of Maritime Research. 2012. Vol. 9. N. 2. pp. 67-72.

[24] Riola, J., Pérez, R. and Díaz, J. Los factores humanos en el proceso de selección y diseño del casco. Revista Ingeniería Naval. 2013. June. pp. 64-73.

[25] Salvesen, N. et al. Ship motions and sea loads. Trans. SNAME. 1970. 78, 250-287.

[26] Sclavounos, P.D. Computation of wave-hip interaction. Advances in Marine Hydrodynamics, ed. by Ohkusu, 1996.

[27] SHIPFLOW. Users manual, Rev. 2.4, FLOWTECH. 1999. Gothenburg, Sweden.

[28] Tang, H.Y., Huilong Ren, H. and Zhong, Q. Design and model test of structural monitoring and assessment system for trimaran. BRODOGRADNJA. Vol. 70. N. 2. pp. 111-134. 2019. https://doi.org/10.21278/brod70206

Submitted: $\quad$ 08.03.2018. Rodrigo Perez Jose M. Riola*

Accepted: $\quad$ 02.12.2019. Universidad Politecnica de Madrid, Av. Arco de la Victoria, 4, Madrid 28040, Spain.

josemaria.riola@upm.es 